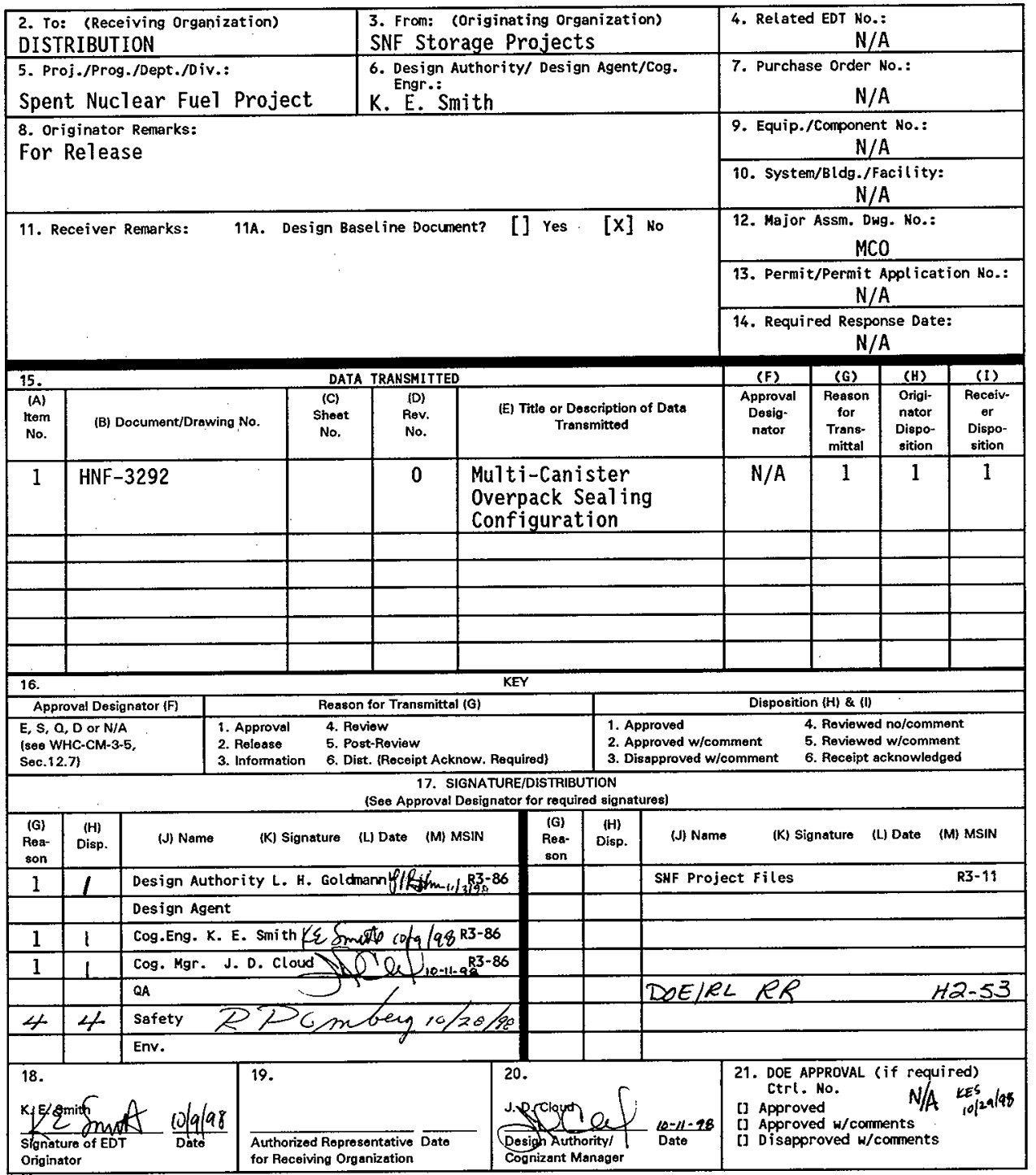

$B D-7400-172-2(05 / 96)$ GEF097 
HNF-3292, Rev. 0

\title{
Multi-Canister Overpack Sealing Configuration
}

\author{
K. E. Smith
}

DE\&S Hanford, Inc., Richland, WA 99352

U.S. Department of Energy Contract DE-AC06-96RL13200

$\begin{array}{lll}\text { EDT/ECN: } & 625780 & \text { UC: } 600 \\ \text { Org Code: } 2 \text { T340 } & \text { Charge Code: } 105532 / \text { AA30 } \\ \text { B\&R Code: } & \text { EW7040000 } & \text { Total Pages: } 9\end{array}$

Key Words: MCO, Spent Fuel, NRC, Packaging, Container, Issue, Mechanical Closure, Redundant Seals

Abstract: The Spent Nuclear Fuel (SNF) position regarding the MultiCanister Overpack (MCO) sealing configuration is to initially rely on an American Society of Mechanica] Engineers (ASME) Section III Subsection NB code compliant mechanical closure/sealing system to quickly and safely establish and maintain full confinement of radioactive materials prior to and during MCO fuel drying activities. Previous studies have shown the mechanical seal to be the preferred closure method, based on dose, cost, and schedule considerations. The cost and schedule impacts of redesigning the mechanical closure to a welded shield plug do not support changing the closure system. The SNF Project has determined that the combined mechanical/welded closure system meets or exceeds the regulatory requirements to provide redundant seals while accommodating key safety and schedule limitations that are unique to $\mathrm{K}$ Basins fuel removal effort.

TRADEMARK DISCLAIMER. Reference herein to any specific comercial product, process, or service by trade name, trademark, manufacturer, or otherwise, does not necessarily constitute or imply its endorsement, recomendation, or favoring by the United States Government or any agency thereof or its contractors or subcontractors.

Printed in the United States of America. To obtain copies of this document, contact: Document Control Services, P.O. 80x 950, Mailstop H6-08, Richland WA 99352, Phone (509) 372-2420; Fax (509) 376-4989.
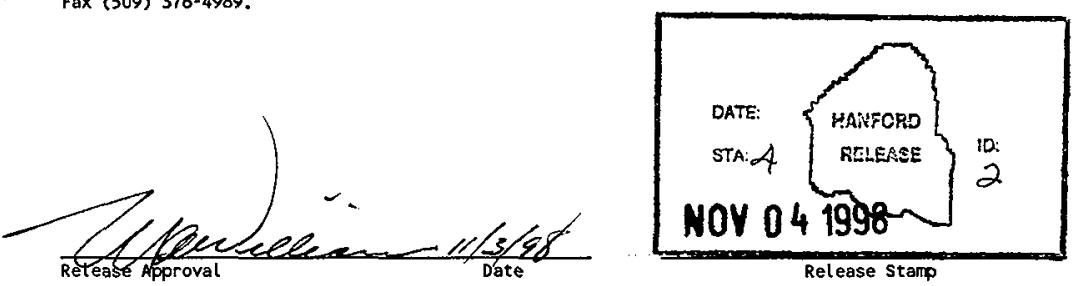

Approved for Public Release 
HNF-3292, Rev. 0

\section{Issue Closure Package}

Issue: MCO Sealing Configuration

Lead:

K. E. Smith

MCO Implementation

Manager, DE\&S Hanford

\section{Approvals:}

Chief Engineer:

A. M. Segrest

DE\&S Hanford

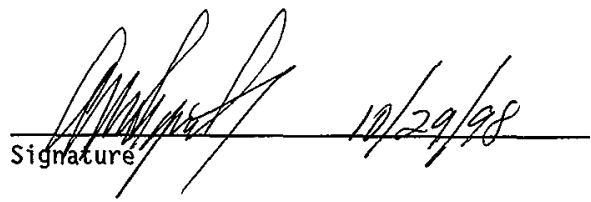

Technical Operations:

J. A. Swenson

Manager

DE\&S Hanford

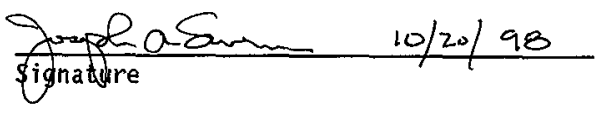

Construction Projects:

A. R. Hollins

Manager

DE\&S Hanford

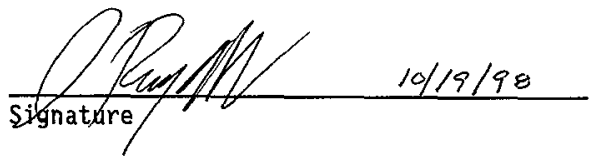

Nuclear Safety:

Robert G. Morgan

Manager

DE\&S Hanford

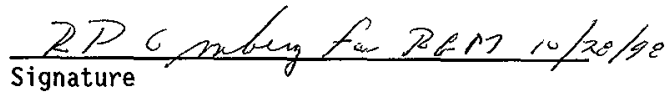

MCO Design Authority:

L. H. Goldmann

DE\&S Hanford

Goun 1181dmonn $10 / 9 / 98$

Signature 
HNF-3292, Rev.0

\author{
MULTI-CANISTER OVERPACK
}

SEALING CONFIGURATION

$\underline{\text { SUMMARY }}$

The Spent Nuclear Fuel (SNF) position regarding the MCO sealing configuration is to initially rely on an American Society of Mechanical Engineers (ASME) Section III Subsection NB code compliant mechanical closure/sealing system to quickly and safely establish and maintain full confinement of radioactive materials prior to and during MCO fuel drying activities. Previous studies have shown the mechanical seal to be the preferred closure method, based on dose, cost, and schedule considerations. The cost and schedule impacts of redesigning the mechanical closure to a welded shield plug do not support changing the closure system.

After transport of the MCO to the Canister Storage Building (CSB), a cover cap will be installed over the mechanical closure system to provide a redundant seal. An ASME Section III Subsection NB code compliant structural weld will be used to install this final cover cap. This weld will be examined with multiple pass liquid penetrant testing. A mass spectrometer helium leak test of the final weld will also be performed.

The SNF project position was carefulty evaluated against applicable regulatory requirements, historical regulatory interpretations, and commercial industry practice/precedent. Though this selected approach is not precisely aligned with previous commercial application of the regulatory requirement 10CFR72.236(e) to provide redundant sealing of confinement systems for commercial SNF storage systems, the SNF Project has determined that the approach meets or exceeds the intent of the regulations while accommodating key safety and schedule limitations that are unique to $\mathrm{K}$ Basins fuel removal effort.

\title{
STATEMENT OF ISSUE
}

The sealing configuration of the MCO consists of a metallic seal captured by a mechanical closure system and a cover cap welded over the mechanical closure with a full penetration, circumferential weld. This sealing configuration must comply with the NRC requirement to provide a redundant seal (redundancy ensures reliability) for the confinement system. Additionally, the continued 
HNF-3292, Rev.0

use of the mechanical closure should provide cost and schedule advantages over a welded shield plug.

\section{BASIS FOR CLOSURE}

Resolution of this issue is based on demonstrating that the MCO sealing configuration meets all applicable requirements in providing a reliable seal and that changing the design to an all-welded closure has unacceptable cost and schedule impacts.

\section{DISCUSSION}

\section{A. Background}

The closure configuration for the $\mathrm{MCO}$ is made up of a mechanical closure system which uses a shield plug/locking ring combination and a separate cover cap which is attached with a structural weld. The mechanical closure is installed immediately following completion of fuel loading into the MCOs. This closure system is depended upon to provide a $1 \times 10^{-5} \mathrm{std} \mathrm{cc} / \mathrm{sec}$ maximum leak rate during transport to the Cold Vacuum Drying (CVD) Facility, processing at the CVD Facility, transport to the CSB, receipt and handling of MCOs at the CSB, gas sampling, and MCO cover Cap welding at the CSB. Leak testing of the mechanical closure system will be performed at the CVD Facility and optionally at the CSB to ensure adequate performance of the helicoflex seal.

Upon receipt at the CSB, the $M C O$ will be placed in the CSB welding station for installation of the final cover cap. The welding station and associated equipment will provide a high quality, automated multi-pass structural weld at the MCO-cover cap interface. The welding equipment and weld process will be fully qualified to ensure consistent performance and compliance with ASME Code requirements. Multiple weld passes will be inspected using dye penetrant surface inspection techniques. Consideration was given to performing an ultrasonic examination of the cover cap weld, but UT examination was not determined to be justified for this application. A discussion of this position is contained in closure package HNF-3293. Following the nondestructive examinations of the weld, a mass spectrometer hel ium leak test will be performed on the cover cap weld to demonstrate leak tightness to $1 \mathrm{x}$ $10^{-7} \mathrm{scc} / \mathrm{sec}$. The liquid penetrant examinations will provide documented evidence of proper weld integrity while the helium leak test will provide confirmation of the containment boundary.

\section{B. Commercial Industry Perspective}

NRC regulations for commercial independent spent fuel storage installations (10CFR72) require that a redundant closure system be incorporated into the storage casks. The regulations also call for monitoring of this system to allow for recovery action following seal failure in order to maintain a safe storage configuration. As discussed below, the seal monitoring requirement has been waived in commercial applications which rely on welded closure 
HNF-3292, Rev.0

systems. Closer inspection of the regulatory bases for the redundant sealing indicates a desire to prevent fission gas release and loss of inert atmosphere during storage. The inert atmosphere primarily serves to prevent degradation of the SNF cladding material. Fission gas release and cladding degradation are considerably less applicable to the $\mathrm{N}$ Reactor fuel due to its already (seriously) degraded condition. Under the MCO sealing strategy, sealing features of the MCO are primarity intended to prevent oxygen ingress and the loss of radioactive particulate from the MCO container during transport and during long term storage.

There are several certified commercial SNF cask storage systems that utilize a continuously monitored double 0-ring mechanical closure seal design.

Nonetheless, NRC has waived the continuous monitoring requirement in several certified container-based storage systems where welded closures are used in place of the mechanical 0-ring seals. This approach allows for a simpler closure design which leads to lower fabrication costs for the disposable inner container component. While the welding operations typically require up to 20 hours of operation for a 60-inch diameter cask with an automated welder, elimination of the equipment, maintenance, and personnel requirements associated with a monitoring system and the expected improved overall performance of the storage system more than justify the initial investment in welding operations. Additionally, since a typical commercial fuel loading operation occurs about ance every 3 months in an environment that is radiologically much less hazardous than the $\mathrm{K}$ Basins, the schedule and dose consequences of the lengthy welding and drying activities are easily managed. With appropriate levels of inspection and redundancy, NRC has ruled that such welded closure systems approach the performance of the factory seam and plate welds on the storage container itself, and as such are not subject to the leakage concerns applied to simple O-ring mechanical seals.

\section{Regulatory Equival ence}

While not representing a direct application of either commercial precedent discussed above, the sealing configuration for the MCOs does provide two high quality closure systems:

- An ASME Section III compliant mechanical closure system which quickly establishes confinement prior to CVD processing and transport, and

- A final cover cap attached with an ASME Section III code compliant structural weld to ensure containment integrity during long term storage.

The mechanical closure system of the $M C O$ is designed to serve multiple prestorage functions, allows for future fuel accessibility if necessary, and provides a considerably more reliable sealing configuration than the simple o-ring systems employed in commercial shipping and storage casks. It also retains the documented radiological and schedule advantages of the current 
HNF-3292, Rev.0

technical baseline to perform an expedited closure of the MCOs at the K Basins.

The welded cover cap provides a final closure system that is essentially equivalent to the factory seam and bottom plate welds of the MCO container itself (i.e., $10^{-7} \mathrm{std} \mathrm{cc} / \mathrm{sec}$ ). The intended purpose of preventing radiological release and exposure during both the pre-storage activities and throughout the long term storage period is met with this MCO closure configuration.

\section{Technical Justification}

When compared with the simple 0-ring mechanical closure systems utilized in the commercial industry, the mechanical seal provided with the MCO is clearly a more robust closure system designed to perform under extreme temperature and pressure conditions. Seal design, capture features, preload forces, and leak paths all contribute to a very low probability for release of radioactive material from the MCO. Individual shield plug ports are outfitted with both mechanically sealed valves with " $C$ " section 0 -ring seals and single " $C$ " section 0-ring cover $\mathrm{plate}$ seals, representing additional seal redundancy in these locations. It should be noted al so that two of the four access ports are designed with high-efficiency particulate air filtration inside the MCOs to further limit the likelihood of a particulate release.

Use of the mechanical/welded sealing configuration significantly enhances the long term operational flexibility of the MCO system. Future access to the MCO contents for monitoring, sampling, repackaging, or further processing would simply involve a single cutting or grinding operation at the cover cap weld or penetration as appropriate. Only minor reconditioning of the weld joints will be needed to allow reuse of all MCO components. Obtaining access to a double welded MCO would require significantly more complex and destructive cutting operations that will likely preclude any reuse of the MCO components.

\section{E. Evaluation of Changing to Welded Shield Plug}

The SNF Project decision in late fiscal year 1996 to utilize a mechanical closure system for the pre-storage activities was driven by several technical challenges that are unique to the facilities, the Project schedule constraints, and the spent fuel characteristics. An extensive study was performed which concluded that a mechanical seal installed at the $K$ Basins would represent the most cost, dose, and time effective approach to shipping and delivering a sealed MCO to the CVD facility ready for processing (Reference 1). The requirement to move $400 \mathrm{MCOs}$ from the basins in a short two-year period was the primary driver for the baseline position established earlier in the SNF Project to avoid time consuming welding operations and potential weld repair delays in the K Basins or at the CVD facility.

The SNF Project was requested by RL to provide justification for continuing with the mechanical closure in late 1997. The SNF Project reviewed the issue 
HNF-3292, Rev.0

at that time and the response was included in the Baseline Change Request BCR006 , Attachment 9-4 (Reference 2). The review concluded that welding in the Basins would have a significantly greater impact on the SNF Project than welding at the CVD. Issues identifed included:

- NOC scope currently excludes welding operations

- Lack of ventilation system

- Lack of temperature control system for cask

- Personnel access difficulties

- Weld quality control difficulties

- Higher radiation exposures

- Negative impact on MCO throughput (potential for operational delays)

Regarding incorporating the welding function at the CVD, the schedule impact for modifying the CVD design to permit welding operations was estimated at 3 to 5 months delay in final CVD readiness. The review concluded with the recommendation to continue with the mechanical closure. Specific advantages listed for the mechanical closure system are:

- Provides simple and quick closure of MCO at basins immediately following fuel loading,

- Prevents contamination of cask/MCO annulus during transport from $\mathrm{K}$ Basins to CVD,

- Provides for immediate processing of MCO upon arrival at CVD processing bays,

- Eliminates additional radiological exposure associated with CVD welding activity,

- Increases transport cask and CVD processing bay availability,

- Eliminates vulnerability associated with weld repairs from the fuel removal path,

- Eliminates cost impacts of additional welding equipment at CVD,

- Eliminates likely cost and schedule impacts of CVD Facility modifications for welding, and

- Provides code compliant joint for pre-storage processing and 1 ifting of MCOs.

Update

The following discussion is not intended to provide an exhaustive review of the mechanical vs. welded closure issue, but rather to summarize the major 
HNF-3292, Rev.0

cost and schedule impacts of changing the closure design at this point in the SNF project.

Changing the closure design from a mechanical seal to a welded shield plug would result in cost savings in MCO fabrication and tooling required for assembly at the basins. Based on the original cost estimates used in the mechanical versus welded cost/benefit study (Reference 1), and considering cost information provided by Oregon Iron Works in January 1998, the potential fabrication cost savings associated with the welded design ranges from $\$ 300 \mathrm{~K}$ to $\$ 870 \mathrm{~K}$ for $400 \mathrm{MCOs}$. Coupled with savings in the tooling, approximately $\$ 1.2 M$ total could be saved in fabrication and tooling by switching to the welded closure design. This savings would be offset by:

- additional cost of welding machines at CVD (4 required) or the basins (2 required) and production welding operations

- training and qualification of welders to operate the automated welding machines

- if welding performed at CVD, cost impact to modify cask to keep unsecured MCO shield plug in place during transfer and to control cask contamination due to water sloshing out the MCO

- if welding at CVD, design and procurement of welding stations and potential redesign of existing equipment to accomodate welding operation and change to process flow (welding performed prior to drying)

- operational cost of performing weld NDE

- cost of revising the SARs and SARP

- cost of redesigning the MCOs, performing drop anaTyses

Considering the cost impacts 1 isted above, the welded closure design does not represent an overali cost savings to the SNF project. The original mechanical vs. welded study (Reference 1) estimated the welding costs at the CVD to be about $\$ 2 M$. Based solely on the cost impacts of welding, a change to a welded closure design is not justified. Consideration of the other cost impacts only widens the gap.

From a schedule perspective, redesigning the MCO closure has a major impact to the MCO Topical and CVD SAR submittal dates. The current MCO Topical schedule shows a November 5, 1998 date for approval by the SNF Project and submittal to RL for review. A change to the MCO design to reflect a welded shield plug would require a minimum 4 month redesign activity, pushing the Topical submittal date out to mid March 1999 . The CVD SAR would be delayed accordingly as it relies on the input from the Topical prior to submittal to $\mathrm{RL}$. As mentioned above, modifying the CVD design to accomodate welding and 
HNF-3292, Rev.0

incorporating the design information into the SAR is a minimum 3 to 5 month activity. The CVD SAR currently shows 11 days of float off critical path. Any delay in this schedule will negatively impact the fuel move start date. The schedule impacts of changing to a welded shield plug do not support maintaining the current SNF high confidence schedule.

\section{REFERENCES}

1. Goldmann, L.H., 1996, Multi-Canister Overpack Closure Comparison Study, WHC-SD-SNF-ES-021, Rev. 0, Westinghouse Hanford Company, Richiand, Washington

2. DESH, Basel ine Change Request 98-006 


\section{DISTRIBUTION COVERSHEET}

Subject: MCO ISSUE PAPERS PER ATTACHED DISTRIBUTION INDEX

\section{DISTRIBUTION}

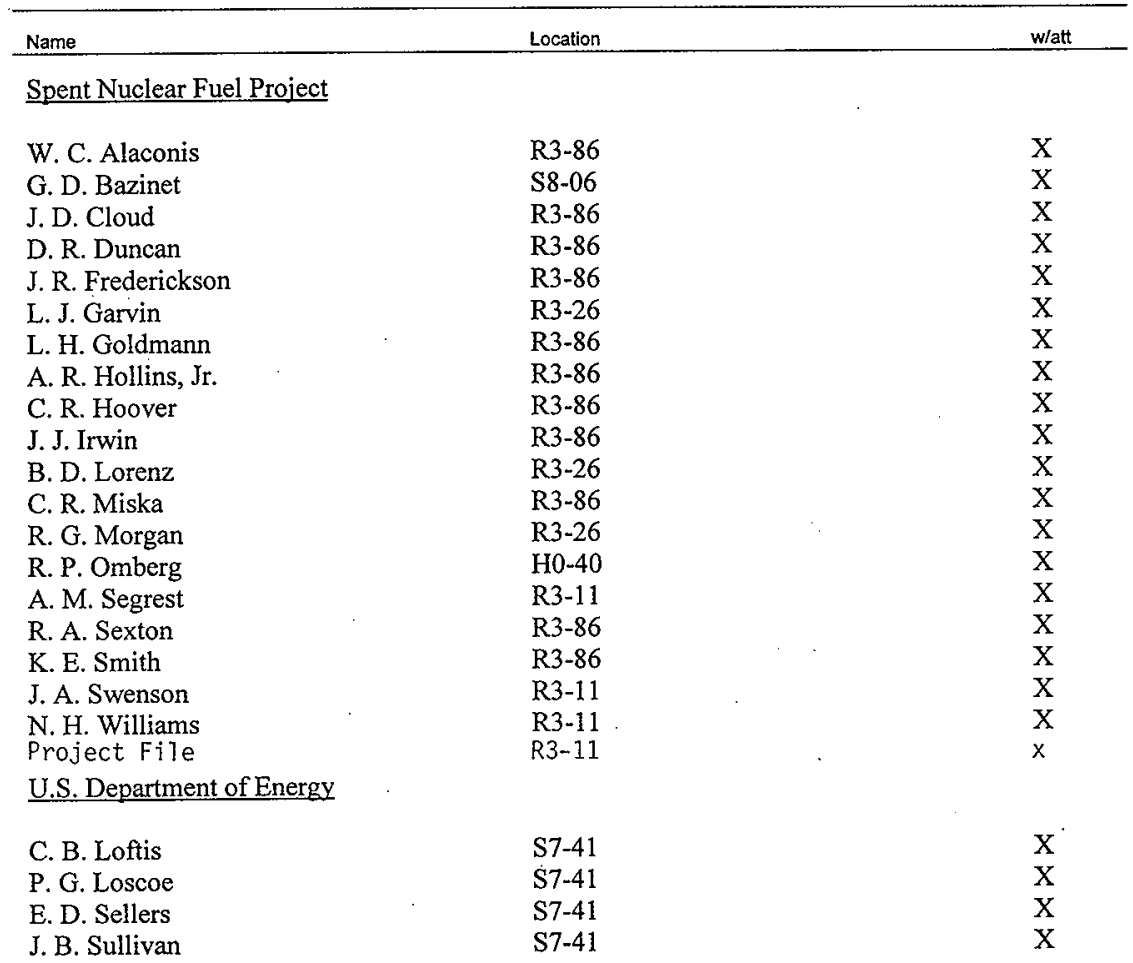




\section{DISTRIBUTION INDEX}

The Multi-Canister Overpack Issue papers listed below are being distributed as a package to facilitate future reference and use by SNF Project personnel. The following issue papers are attached:

1. HNF-2876, Oxygen Gettering Issue Closure Package

2. HNF-3265, MCO Number of Shield Plug Ports

3. HNF-3399, MCO Necessity of the Rupture Disk

4. HNF-3267, MCO Dual Pressure Rating

5. HNF-3293, MCO Ultrasonic Examination of Closure Weld

6. HNF-3354, MCO Monitoring Issue Closure Package and HNF-3312, MCO Monitoring Activity Description

7. HNF-3292, MCO Sealing Configuration

8. HNF-3266, MCO Design Pressure Rating

9. HNF-3255, ASME Code Requirements for MCO Design and Fabrication

10. HNF-3398, MCO Inservice Inspection and Maintenance

11. HNF-3420, MCO Internal HEPA Filters

12. HNF-3036, Low Reactive Surface Area Issue Closure Package

13. HNF-3270, MCO Pressure Testing 